\title{
Bmi-1 induces radioresistance by suppressing senescence in human U87 glioma cells
}

\author{
LAN YE ${ }^{1}$, CUIHONG WANG ${ }^{1}$, GUANYING YU $^{2}$, YUHUA JIANG $^{1}$, DIANSHUI SUN ${ }^{1}$, ZAIYUN ZHANG $^{1}$,

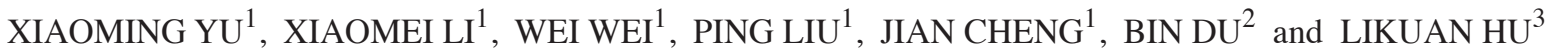 \\ ${ }^{1}$ Cancer Center, The Second Hospital of Shandong University, Jinan, Shandong 250033; ${ }^{2}$ Jinan Central Hospital, Jinan, \\ Shandong 250014; ${ }^{3}$ Department of Radiotherapy, Qilu Hospital, Shandong University, Jinan, Shandong 250012, P.R. China
}

Received July 29, 2014; Accepted September 16, 2014

DOI: $10.3892 / 01.2014 .2606$

\begin{abstract}
Radiotherapy is the main locoregional control modality for a number of types of malignant tumors, including glioblastoma. However, radiotherapy fails to prevent recurrence in numerous patients due to the intrinsic radioresistance of cancer cells. Cell senescence is significant in tumor suppressor mechanisms and is closely associated with the radioresistance of cancer cells. Bmi-1 has been proposed to be an oncogene that can induce anti-senescence in tumor cells. The present study investigated the response of U87 glioma cells to radiation exposure and the role of Bmi-1 in the response following radiotherapy. Cell apoptosis and cell cycle distribution were assessed using flow cytometry, and a SA- $\beta$-Gal stain was used to observe the senescence ratio of U87 cells following radiation. The expression of Bmi-1 in U87 cells exposed to different doses of radiation was evaluated by western blot analysis. X-ray radiation was found to inhibit U87 cell proliferation through the induction of senescence rather than apoptosis. Following exposure to radiation, the cell cycle distribution was dysregulated, with an increased number of cells in the $\mathrm{G}_{2} / \mathrm{M}$ phase, and the expression of Bmi-1 was upregulated, particularly when a dose of $\geq 6$ Gy was administered. The results indicated that senescence is the main mechanism by which U87 cell growth is inhibited following radiation. In addition, Bmi-1 may be significant in increasing the radioresistance of glioma cells by enabling cell senescence.
\end{abstract}

\section{Introduction}

Gliomas are the most common type of brain tumor, worldwide (1). Despite the use of surgery, radiation and conventional chemotherapy, the median survival time of patients with the most malignant type of glioma, glioblastoma, is only

Correspondence to: Mr. Likuan Hu, Department of Radiotherapy, Qilu Hospital, Shandong University, 44 Wenhua Xi Road, Jinan, Shandong 250012, P.R. China

E-mail: 12222494@qq.com

Key words: glioma, Bmi-1, senescence, radiation one year (2). Gliomas may be characterized by resistance to apoptosis and radiation $(3,4)$, however, the mechanism of this process remains unclear.

According to previous studies, certain types of glioma cells, including U87 cells, undergo senescence as opposed to apoptosis following exposure to ionizing radiation (5-7). Cellular senescence is an extremely stable form of cell cycle arrest and constitutes a strong natural tumor suppressor mechanism. At present, the predominant senescence signaling pathways include the p53-p21Cip1/Waf1, p19Arf-Mdm2 and p16Ink4a-Rb pathways (8).

B lymphoma Mo-MLV insertion region 1 homolog (Bmi-1) is a polycomb group protein that regulates cell proliferation and has been found to be upregulated in a variety of human cancer types, including acute myeloid leukemia and breast, colon, lung, ovarian and nasopharyngeal cancer; this suggests a potential role of Bmi-1 as an oncogene (9-12). Bmi-1 has been demonstrated to regulate the expression of the p16Ink4a, hTERT and Hox group genes (13). Overexpression of Bmi-1 may reduce the expression of p16 and p19Arf $(14,15)$, which induce anti-senescence in tumor cells. Bmi-1 has also been reported to be overexpressed in certain gliomas that usually possess a poor prognosis (16-18).

The current study investigated the response of U87 glioma cells to radiation exposure as well as the role of Bmi-1 in their response following radiotherapy.

\section{Materials and methods}

Cell culture. The human glioma cell line U87 was purchased from the Cell Bank of the Chinese Academy of Sciences (Shanghai, China). The glioma cells were maintained in minimum essential medium (GE Healthcare Life Sciences, Logan, UT, USA) containing 10\% fetal bovine serum (FBS; GE Healthcare Life Sciences) and incubated at $37^{\circ} \mathrm{C}$ in a humidified atmosphere of $5 \% \mathrm{CO}_{2}$.

Radiation. The cells were plated on 24-well dishes at a density of $5 \times 10^{4}$ cells $/ 0.5 \mathrm{ml}$ on day 0 . Subsequently, the U87 cells were immediately exposed to X-ray radiation with a linear accelerator source (Elekta, Stockholm, Sweden) at a dose rate of $300 \mathrm{cGy} / \mathrm{min}$. Every $24 \mathrm{~h}$, the number of cells in three wells was quantified using a cell counter (Inno-Alliance 
Biotech, Wilmington, DE, USA) and the mean was calculated. The results are presented as the mean \pm standard error of three independent experiments.

Annexin V-fluorescein isothiocyanate (FITC)/propidium iodide (IPI) double-labeled flow cytometry (FCM). To detect the apoptotic ratio of cells following $72 \mathrm{~h}$ of exposure to X-ray radiation, the expression of Annexin V-FITC (Sigma-Aldrich, St. Louis, MO, USA) and the exclusion of PI (Sigma-Aldrich) were detected by two-color FCM using the LSR Fortessa cell analyzer (Becton-Dickinson, Franklin Lakes, NJ, USA). The U87 cells were collected in Eppendorf PCR tubes, washed twice with phosphate buffered saline (PBS) and resuspended in $500 \mu \mathrm{l}$ binding buffer. The samples were incubated with $5 \mu$ l Annexin V-FITC at room temperature for $10 \mathrm{~min}$ and then $5 \mu \mathrm{l}$ PI was added. Each sample was incubated in the dark for a further $10 \mathrm{~min}$ at room temperature prior to the fluorescence intensity being quantitated by FCM.

Cell cycle. To detect the cell cycle of cells following $72 \mathrm{~h}$ of exposure to radiation, glioma cells were fixed with $70 \%$ ethanol, resuspended in PBS/1\% FBS, and treated with ribonuclease (Beyotime Institute of Biotechnology, Haimen, China). PI was added to the cells and the samples were then analyzed by FCM (Becton-Dickinson). Cell cycle profile analysis of the DNA histograms of integrated red fluorescence was performed with ModFit LT 2.0 (Verity Software, Inc., Topsham, ME, USA).

Senescence-associated $\beta$-galactosidase (SA- $\beta$-Gal) staining. To detect the senescence ratio of cells following $72 \mathrm{~h}$ of exposure to radiation, SA- $\beta$-Gal staining was performed using the SA- $\beta$-Gal Kit (Beyotime Institute of Biotechnology) following the manufacturer's instructions. The cells were considered to be positive when the cytoplasm was stained with SA- $\beta-G a l$.

Western blot analysis. The U87 cells were collected and lysed in lysis buffer $(150 \mathrm{mM} \mathrm{NaCl}, 50 \mathrm{mM}$ Tris with $\mathrm{pH} 7.4,1 \% \mathrm{NP} 40$, $0.1 \%$ SDS, $0.5 \%$ sodium deoxycholate), supplemented with protease inhibitors (CWBio, Inc., Beijing, China) subsequent to $72 \mathrm{~h}$ of exposure to radiation, which was followed by centrifugation at $10,000 \mathrm{x}$ g for $15 \mathrm{~min}$ at $4^{\circ} \mathrm{C}$. The protein concentration in each sample extract was detected using the bicinchoninic acid assay (CWBio, Inc.). SDS-PAGE was performed on 15\% polyacrylamide gels, with $40 \mu \mathrm{g}$ of protein sample per lane. Following electrophoresis, the protein was transferred to nitrocellulose membranes and incubated in 5\% non-fat milk at room temperature for $2 \mathrm{~h}$. Subsequently, the membranes were incubated overnight at $4^{\circ} \mathrm{C}$ with a primary polyclonal rabbit antihuman antibody for Bmi-1 (sc-10745; Santa Cruz Biotechnology, Dallas, TX, USA). Subsequent to being washed three times using PBS, the membrane was incubated with an appropriate concentration of horseradish peroxidase-conjugated anti-rabbit secondary antibody (CWBio, Inc.) for $2 \mathrm{~h}$. Following a further three washes with PBS, the specific protein band was visualized using an enhanced chemiluminescence kit (CWBio, Inc.).

Statistical analysis. Each experiment was conducted in triplicate. Student's T-test was used to evaluate the statistical significance of the differences and a $\mathrm{P}<0.05$ was considered to indicate a statistically significant difference.

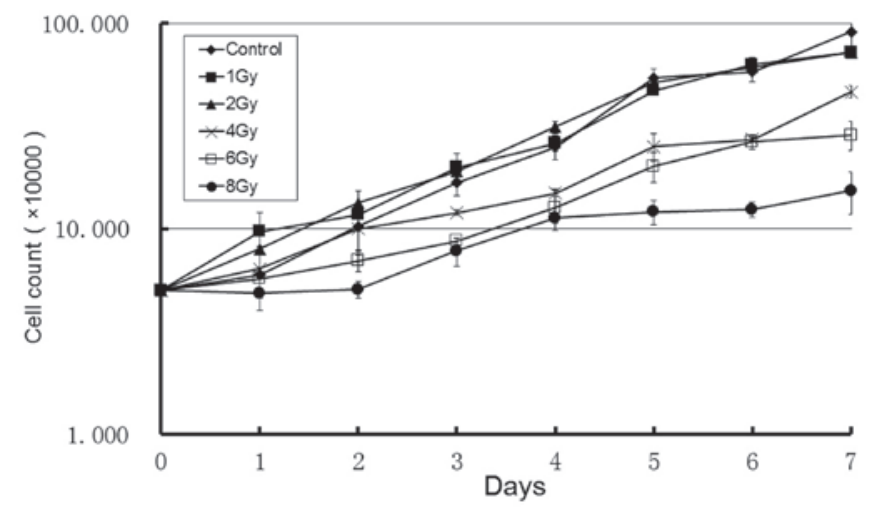

Figure 1. Cell growth curves of U87 glioma cells following exposure to $\mathrm{X}$-ray radiation. The cells were plated on 24-well dishes at a density of $5 \times 10^{4}$ cells $/ 0.5 \mathrm{ml}$ on day 0 and immediately exposed to X-ray radiation at various doses. Every $24 \mathrm{~h}$, the number of cells was quantified using a cell counter. The results are presented as the mean \pm standard error of three independent experiments.

\section{Results}

Proliferation inhibition in U87 glioma cells following X-ray radiation exposure. To determine the cellular proliferation of U87 cells following exposure to radiation, the U87 cells were treated with X-ray radiation at 1,2,4.6 and 8 Gy (Fig. 1). Cellular proliferation was observed to be inhibited in a dose-dependent manner at doses $\geq 4 \mathrm{~Gy}$. No significant inhibition of cellular proliferation was observed in the control, 1 and 2 Gy groups. Following $24 \mathrm{~h}$ of exposure to X-ray radiation, the number of cells in the groups receiving doses of 1 and 2 Gy X-ray radiation was increased compared with the control groups $(\mathrm{P}<0.05)$.

Apoptosis and senescence in U87 glioma cells following exposure to X-ray radiation. To evaluate whether the cellular proliferation inhibition of $\mathrm{U} 87$ cells in response to X-ray radiation is associated with apoptosis or senescence, U87 cells were treated with X-ray radiation at 1, 2,4.6 and $8 \mathrm{~Gy}$. Following $72 \mathrm{~h}$ of exposure to radiation, no significant apoptosis was identified in any of the groups (Fig. 2). Using SA- $\beta$-Gal staining, it was observed that senescence had occurred in all treatment groups in a dose-dependent manner (Fig. 3B). Under phase-contrast microscopy, the senescent morphology of a large and flattened shape was observed (Fig. 3A). These morphological changes were more evident in the cells that were exposed to radiation doses of $\geq 6$ Gy.

The change of cell cycle phase in U87 glioma cells following exposure to $X$-ray radiation. Following $72 \mathrm{~h}$ of exposure to X-ray radiation, the cell cycle phases of U87 cells were analyzed (Fig. 4). The proportion of cells in the $S$ phase was increased in all of the treatment groups $(\mathrm{P}<0.05)$. The proportion of cells in the $\mathrm{G}_{2} / \mathrm{M}$ phase was decreased in the 1 and $2 \mathrm{~Gy}$ groups and increased in the 6 and 8 Gy groups $(\mathrm{P}<0.05)$. No significant difference was identified in the $\mathrm{G}_{0} / \mathrm{G}_{1}$ phase between the 1,2,4 Gy and control groups, however, this was increased in the 6 and 8 Gy groups.

Expression of Bmi-1 in U87 glioma cells following exposure to $X$-ray radiation. To observe whether the 

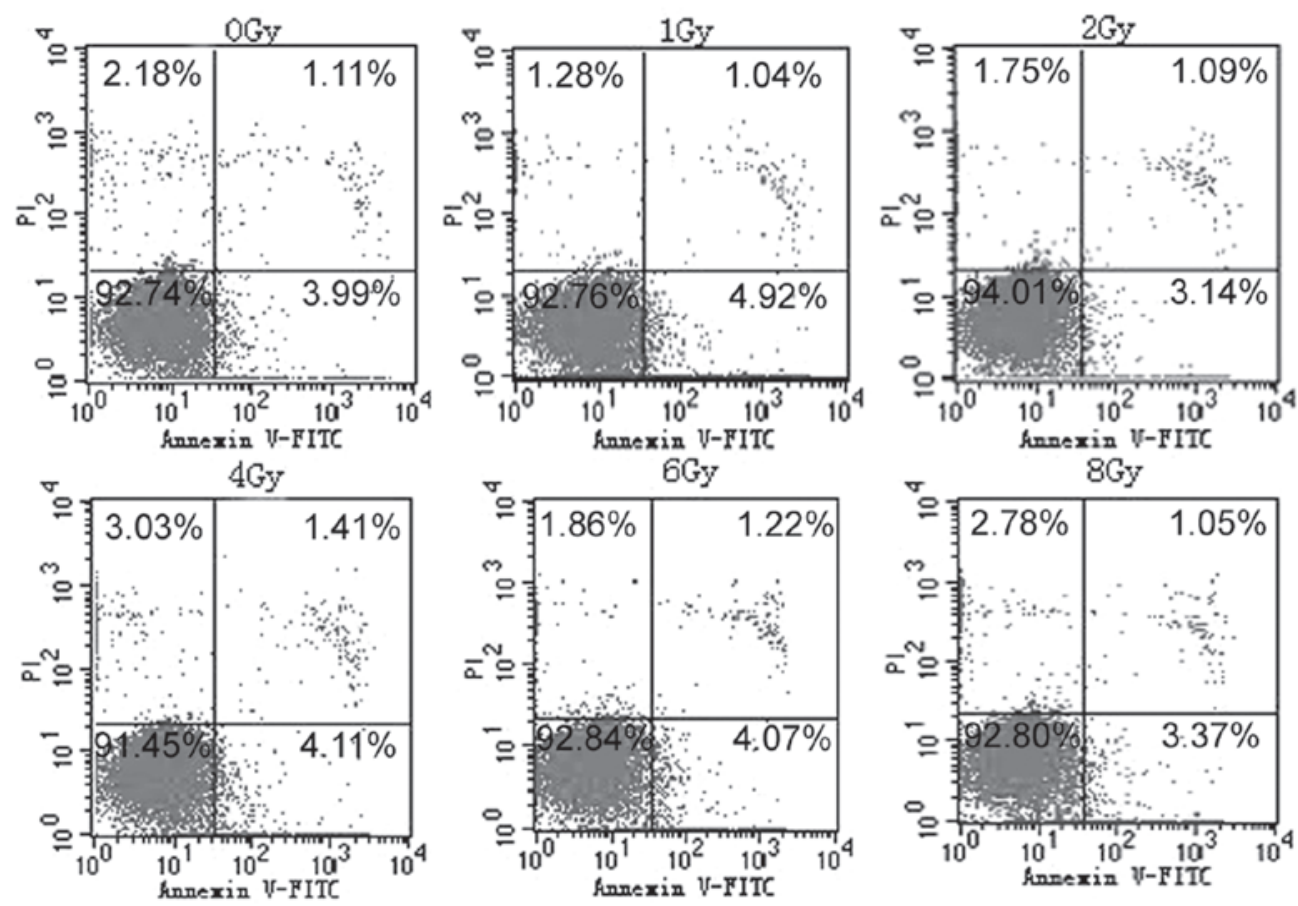

Figure 2. Cell apoptosis. Following $72 \mathrm{~h}$ of exposure to X-ray radiation at various doses, the U87 glioma cells were assessed by Annexin V-fluorescein isothiocyanate/propidium iodide double staining.

A
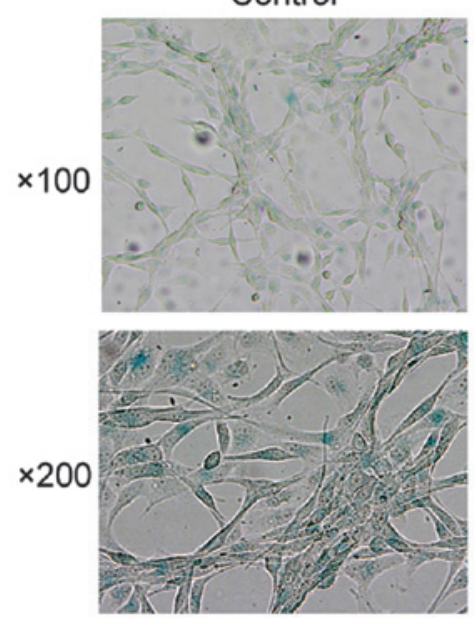

2 Gy
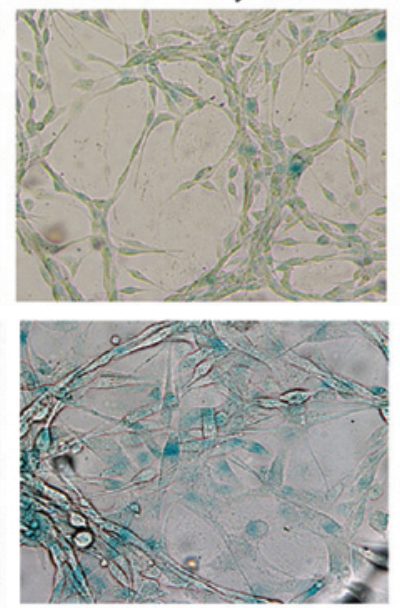

8 Gy
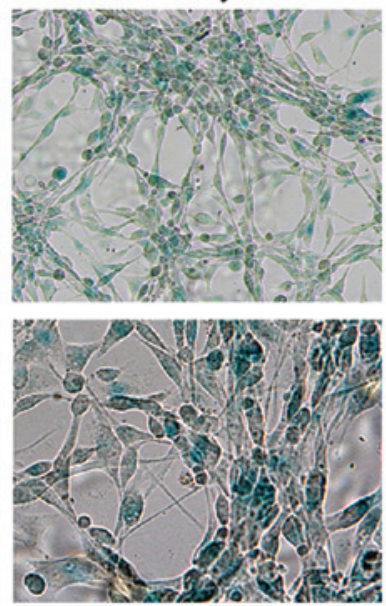

B

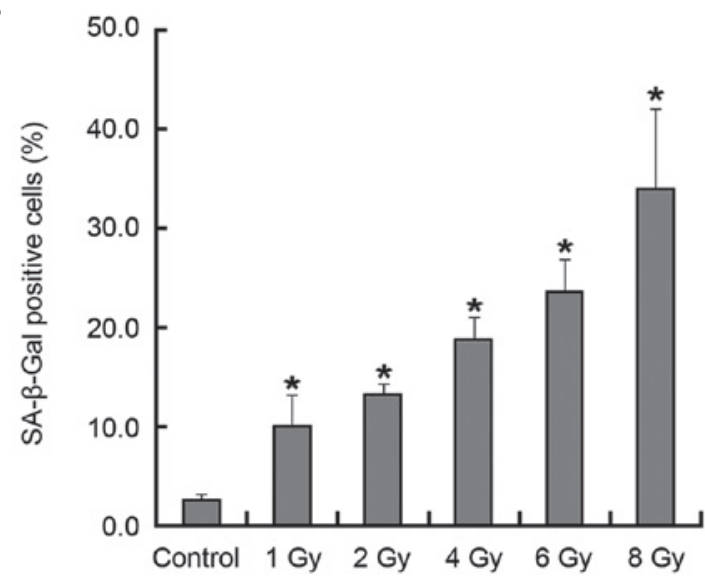

Figure 3. Cell senescence. (A) Following $72 \mathrm{~h}$ of exposure to X-ray radiation at various doses, the U87 glioma cells were treated by SA- $\beta$-Gal staining and images were captured under phase-contrast microscopy. (B) Under the microscope the SA- $\beta$-Gal positive cells were counted and the quantitative results are presented as the mean \pm standard deviation of three independent experiments. ${ }^{*} \mathrm{P}<0.05$ vs. control. 


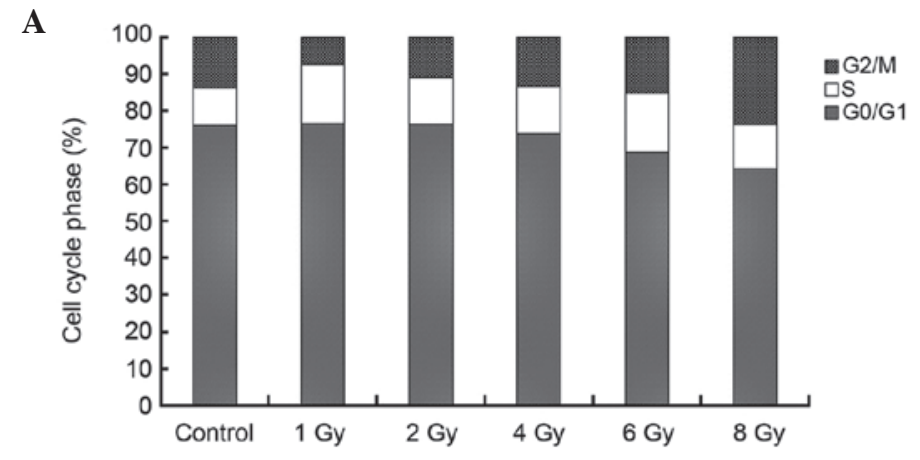

B
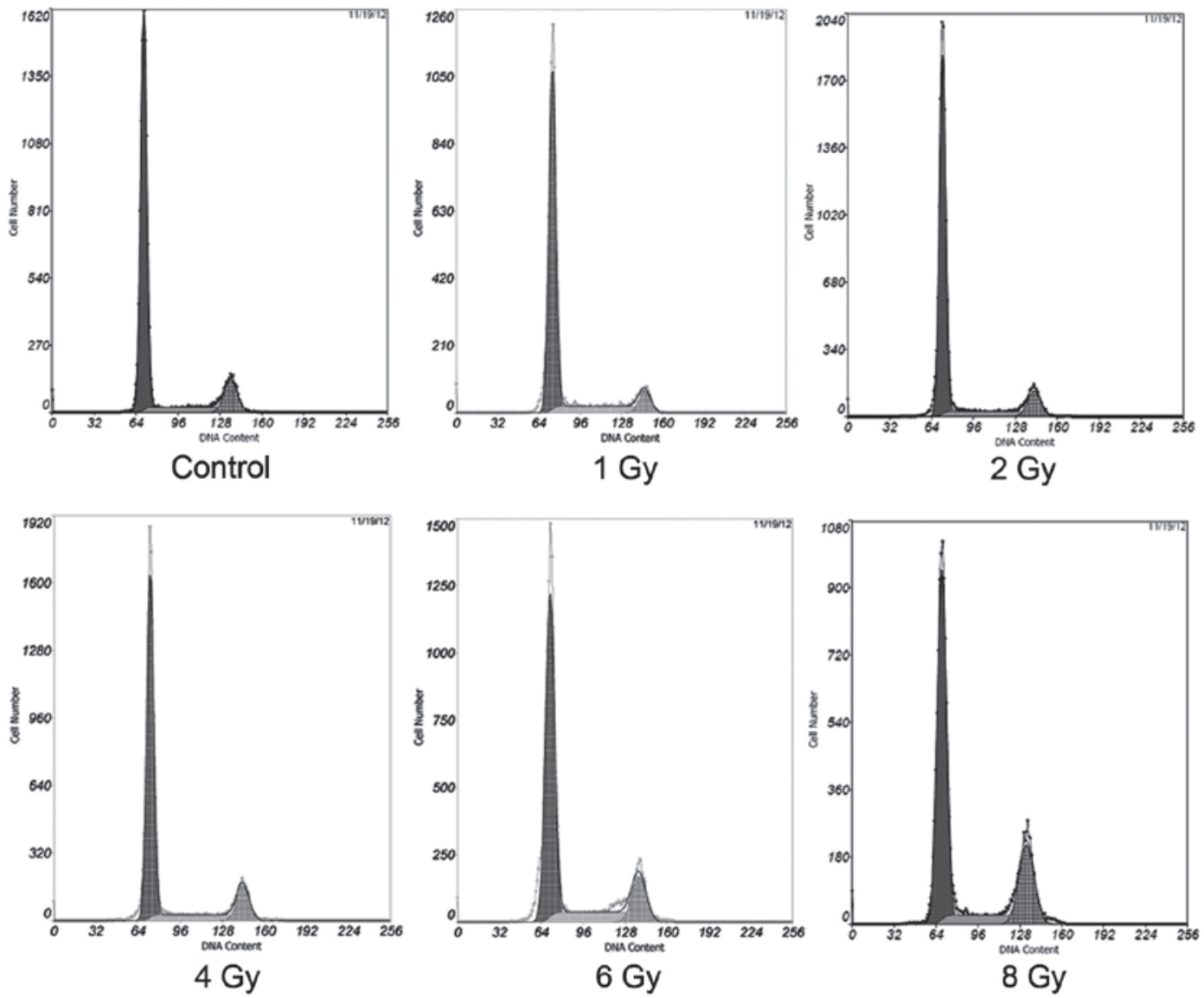

Figure 4. Cell cycle. (A) Following $72 \mathrm{~h}$ of exposure to X-ray radiation at various doses, the U87 glioma cells were assessed by propidium iodide staining and analyzed to generate a cell cycle profile. (B) The columns provide the mean of three independent experiments. " $\mathrm{P}<0.05$ vs. control.

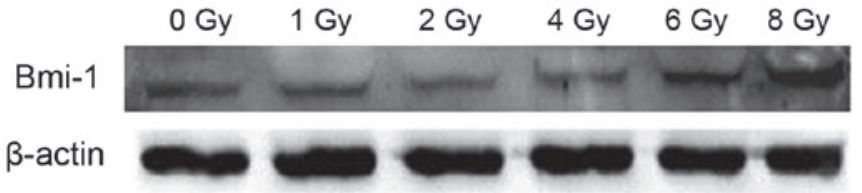

Figure 5. Western blot analysis demonstrating that ionizing radiation increased Bmi-1 expression. $\beta$-actin was used as a loading control.

expression of Bmi-1 was associated with exposure to X-ray radiation, $\mathrm{U} 87$ cells were exposed to $\mathrm{X}$-ray radiation in doses of 1, 2, 4.6 and $8 \mathrm{~Gy}$. Following $72 \mathrm{~h}$ of exposure to radiation, the expression of Bmi-1 was determined (Fig. 5). Bmi-1 expression was increased in the 6 Gy and 8 Gy groups $(\mathrm{P}<0.05)$.
No significant difference in Bmi-1 expression was observed between the 1,2 and $4 \mathrm{~Gy}$ and control groups.

\section{Discussion}

Glioma is the most common malignant brain tumor in adults, worldwide (19), with grade IV glioblastoma being the most fatal $(20,21)$. Radiation is an important therapy for glioma patients, however, the resistance of gliomas to radiation has affected the response to treatment (22). If the mechanism of radiation resistance is identified, novel treatment options for radiation-resistant gliomas may be investigated to improve the response to radiation treatment. U87 cells were selected for investigation in the current study as they are a human glioblastoma cell line that is characterized by resistance to apoptosis and radiation. 
Radiotherapy is significant in the treatment of glioma. Numerous studies have focused on the more effective method of increasing the radiosensitivity of glioma (23-25). Radiation causes DNA damage to cells and subsequently induces apoptosis, senescence or death. Apoptosis is known to be an important mechanism for radiotherapy and chemotherapy, however, the present study and others have demonstrated that radiation did not induce apoptosis in certain gliomas, but instead induced senescence $(5,26,27)$.

Cellular senescence is characterized by irreversible cell cycle arrest, with morphological changes that result in a large and flattened cell shape. Senescent cells remain metabolically active and exhibit certain properties, including SA- $\beta$-Gal staining based on lysosomal $\beta$-galactosidase activity at $\mathrm{pH}$ 6.0, resistance to apoptosis and altered gene expression (28). Tumor cells have been hypothesized to possess the ability to elude senescence. Therefore, it is possible that improved tumor treatments may be developed by understanding the underlying mechanism of senescence (29). The importance of cellular senescence as a tumor suppression mechanism is increasingly being recognized.

Bmi-1 may be significant in the senescence of tumor cells (30). Bmi-1 negatively controls the expression of the p16 gene (31,32); p16 expression is one of the hallmarks of cellular senescence (33) and inhibits the activity of CDK4, which is the key enzyme in the $\mathrm{G}_{1}-\mathrm{S}$ transformation during cell division, preventing the cells from entering $\mathrm{S}$ phase. Once p16 is mutationally or transcriptionally inactivated in cells, CDK4 is uncontrolled, leading to malignant proliferation. The tumor suppressor gene, p16, is often mutationally and transcriptionally inactivated in gliomas. In addition, Bmi-1 can induce the coordination of the c-myc gene with p16 to promote cell transformation and tumor formation, which results in the cell escaping apoptosis (34). For these reasons, Bmi-1 presents an attractive target for glioma therapy.

The aim of the present study was to elucidate whether Bmi-1 expression was associated with the senescence of the U87 glioma cells that have been exposed to X-ray radiation. $\mathrm{X}$-ray radiation was unable to induce apoptosis in U87 glioma cells. However, X-ray radiation was able to induce senescence, resulting in the inhibition of U87 cell proliferation following exposure to the radiation at a dose of $\geq 4 \mathrm{~Gy}$. An increase in the proportion of cells in the $\mathrm{S}$ phase was observed following exposure to various doses of $\mathrm{X}$-ray radiation. In addition, in the groups exposed to the lower doses of 1,2 and $4 \mathrm{~Gy}$, the proportion of cells in the $\mathrm{G}_{2} / \mathrm{M}$ phase was decreased or not significantly different compared with the control group. Furthermore, the proportion of cells in the $\mathrm{G}_{0} / \mathrm{G}_{1}$ phase was not significantly different compared with the control group. When cell senescence is induced, the cell cycle should arrest in $\mathrm{G}_{1}$ phase. This may be the reason that the proportion of cells in the $G_{0} / G_{1}$ phase remained stable despite the increase in the proportion of cells in the $\mathrm{S}$ phase. However, in the higher dose group, exposed to 6 and $8 \mathrm{~Gy}$, the proportion of cells in the $\mathrm{G}_{2} / \mathrm{M}$ phase was increased and the proportion of cells in the $\mathrm{G}_{0} / \mathrm{G}_{1}$ phase was markedly decreased. Although the proportion of cells that were SA- $\beta$-Gal positive was greater when compared with the control and other radiation groups, which means that an increased number of U87 cells underwent senescence, the U87 cells did not arrest in the $\mathrm{G}_{1}$ phase and continued to the $S$ and $\mathrm{G}_{2} / \mathrm{M}$ phases. It appeared that certain factors aid U87 cells in evading senescence following exposure to higher doses of X-ray radiation. In the present study, Bmi-1 expression was observed to be significantly increased in the higher dose (6 and 8 Gy) groups and therefore, may exert an effect that aids the cells in evading cell cycle arrest. However, the mechanism associated with this progress is not fully understood.

In the present study, senescence was determined as the main mechanism of U87 cell growth suppression following exposure to X-ray radiation. Bmi-1 may be significant in the radioresistance of U87 cells by suppressing senescence. Future studies focusing on the expression of Bmi-1 and its downstream genes, using gene transfection technology in additional glioma cell lines, may aid in determining the possible mechanism of Bmi-1 in the radioresistance of glioma cells.

\section{Acknowledgements}

The present study was supported by Youth Foundation in the Second Hospital of Shandong University (grant no. Y2013010016), Jinan University Institutes Independent Innovation Plan (grant no. 201401263), Development Project of Shandong Province Science and Technology of Traditional Chinese Medicine (grant no. 2007-140) and Shandong Province Natural Science Foundation of China (grant no. 2012zre27087).

\section{References}

1. Louis DN, Ohgaki H, Wiestler OD, et al: The 2007 WHO classification of tumours of the central nervous system. Acta Neuropathol 114: 97-109, 2007.

2. Ohgaki H, Dessen P, Jourde B, et al: Genetic pathways to glioblastoma: a population-based study. Cancer Res 64: 6892-6899, 2004.

3. Cancer Genome Atlas Research Network: Comprehensive genomic characterization defines human glioblastoma genes and core pathways. Nature 455: 1061-1068, 2008.

4. Ohgaki $\mathrm{H}$ and Kleihues P: Genetic alterations and signaling pathways in the evolution of gliomas. Cancer Sci 100: 2235-2241, 2009.

5. Lee JJ, Kim BC, Park MJ, et al: PTEN status switches cell fate between premature senescence and apoptosis in glioma exposed to ionizing radiation. Cell Death Differ 18: 666-677, 2011.

6. Quick QA and Gewirtz DA: An accelerated senescence response to radiation in wild-type p53 glioblastoma multiforme cells. J Neurosurg 105: 111-118, 2006.

7. Nam HY, Han MW, Chang HW, et al: Radioresistant cancer cells can be conditioned to enter senescence by mTOR inhibition. Cancer Res 73: 4267-4277, 2013.

8. Hwang ES, Yoon G and Kang HT: A comparative analysis of the cell biology of senescence and aging. Cell Mol Life Sci 66: 2503-2524, 2009.

9. Chowdhury M, Mihara K, Yasunaga S, Ohtaki M, Takihara Y and Kimura A: Expression of Polycomb-group (PcG) protein BMI-1 predicts prognosis in patients with acute myeloid leukemia. Leukemia 21: 1116-1122, 2007.

10. Vonlanthen S, Heighway J, Altermatt HJ, et al: The Bmi-1 oncoprotein is differentially expressed in non-small cell lung cancer and correlates with INK4A-ARF locus expression. Br J Cancer 84: 1372-1376, 2001.

11. Zhang FB, Sui LH and Xin T: Correlation of Bmi-1 expression and telomerase activity in human ovarian cancer. Br J Biomed Sci 65: 172-177, 2008.

12. Song LB, Li J, Liao WT, et al: The polycomb group protein Bmi-1 represses the tumor suppressor PTEN and induces epithelial-mesenchymal transition in human nasopharyngeal epithelial cells. J Clin Invest 119: 3626-3636, 2009. 
13. Guo BH, Feng Y, Zhang R, et al: Bmi-1 promotes invasion and metastasis, and its elevated expression is correlated with an advanced stage of breast cancer. Mol Cancer 10: 10, 2011.

14. Dhawan S, Tschen SI and Bhushan A: Bmi-1 regulates the Ink4a/Arf locus to control pancreatic beta-cell proliferation. Genes Dev 23: 906-911, 2009.

15. Bruggeman SW, Hulsman D, Tanger E, et al: Bmil controls tumor development in an Ink4a/Arf-independent manner in a mouse model for glioma. Cancer Cell 12: 328-341, 2007.

16. Glinsky GV, Berezovska O and Glinskii AB: Microarray analysis identifies a death-from-cancer signature predicting therapy failure in patients with multiple types of cancer. J Clin Invest 115 1503-1521, 2005.

17. Häyry V, Tynninen O, Haapasalo HK, et al: Stem cell protein BMI-1 is an independent marker for poor prognosis in oligodendroglial tumours. Neuropathol Appl Neurobiol 34: 555-563, 2008

18. Li J, Gong LY, Song LB, et al: Oncoprotein Bmi-1 renders apoptotic resistance to glioma cells through activation of the IKK-nuclear factor-kappaB pathway. Am J Pathol 176: 699-709, 2010.

19. Taylor LP: Diagnosis, treatment, and prognosis of glioma: five new things. Neurology 75: S28-S32, 2010.

20. Stupp R, Mason WP, van den Bent MJ, et al; European Organisation for Research and Treatment of Cancer Brain Tumor and Radiotherapy Groups; National Cancer Institute of Canada Clinical Trials Group: Radiotherapy plus concomitant and adjuvant temozolomide for glioblastoma. N Engl J Med 352: 987-996, 2005.

21. Clarke J, Butowski N and Chang S: Recent advances in therapy for glioblastoma. Arch Neurol 67: 279-283, 2010.

22. Stupp R, Hegi ME, Mason WP, et al; European Organisation for Research and Treatment of Cancer Brain Tumour and Radiation Oncology Groups; National Cancer Institute of Canada Clinical Trials Group: Effects of radiotherapy with concomitant and adjuvant temozolomide versus radiotherapy alone on survival in glioblastoma in a randomised phase III study: 5-year analysis of the EORTC-NCIC trial. Lancet Oncol 10: 459-466, 2009.
23. Xie C, Wang H, Cheng H, Li J, Wang Z and Yue W: RAD18 mediates resistance to ionizing radiation in human glioma cells. Biochem Biophys Res Commun 445: 263-268, 2014.

24. Liu P, Huang Z, Chen Z, et al: Silver nanoparticles: a novel radiation sensitizer for glioma? Nanoscale 5: 11829-11836, 2013.

25. Naidu MD, Mason JM, Pica RV, Fung H and Peña LA: Radiation resistance in glioma cells determined by DNA damage repair activity of Ape1/Ref-1. J Radiat Res 51: 393-404, 2010.

26. Jendrossek V: The intrinsic apoptosis pathways as a target in anticancer therapy. Curr Pharm Biotechnol 13: 1426-1438, 2012.

27. Dewey WC, Ling CC and Meyn RE: Radiation-induced apoptosis: relevance to radiotherapy. Int J Radiat Oncol Biol Phys 33: 781-796, 1995

28. Schmitt CA: Cellular senescence and cancer treatment. Biochim Biophys Acta 1775: 5-20, 2007.

29. Roninson IB: Tumor cell senescence in cancer treatment. Cancer Res 63: 2705-2715, 2003.

30. Li Y, Hu J, Guan F, et al: Copper induces cellular senescence in human glioblastoma multiforme cells through downregulation of Bmi-1. Oncol Rep 29: 1805-1810, 2013.

31. Jacobs JJ, Kieboom K, Marino S, DePinho RA and van Lohuizen M: The oncogene and Polycomb-group gene Bmi-1 regulates cell proliferation and senescence through the ink4a locus. Nature 397: 164-168, 1999.

32. Jiang L, Li J and Song L: Bmi-1, stem cells and cancer. Acta Biochim Biophys Sin (Shanghai) 41: 527-534, 2009.

33. Hara E, Smith R, Parry D, Tahara H, Stone S and Peters G: Regulation of p16CDKN2 expression and its implications for cell immortalization and senescence. Mol Cell Biol 16 859-867, 1996.

34. Molofsky AV, Pardal R, Iwashita T, Park IK, Clarke MF and Morrison SJ: Bmi-1 dependence distinguishes neural stem cell self-renewal from progenitor proliferation. Nature 425: 962-967, 2003. 